\title{
Somatostatin Reduces the Acute Lung Injury of Mice via Increasing the Affinity of Glucocorticoid Receptor
}

\author{
Yan Zhao Min Zhang $^{\mathrm{b}}$ Ren-Ping Xiong ${ }^{\mathrm{a}}$ Xing-Yun Chen ${ }^{\mathrm{a}}$ Ping Li ${ }^{\mathrm{a}}$ Ya-Lei Ning ${ }^{\mathrm{a}}$ \\ Nan Yanga Yan Peng ${ }^{\text {a }}$ Yuan-Guo Zhou ${ }^{\mathrm{a}}$ \\ aMolecular Biology Center, the State Key Laboratory of Trauma, Burns and Combined Injury, Research \\ Institute of Surgery and Daping Hospital, Third Military Medical University, Chongqing, ${ }^{\text {bDepartment of }}$ \\ Otolaryngology, Research Institute of Surgery and Daping Hospital, Third Military Medical University, \\ Chongqing, China
}

\section{Key Words}

Acute Lung Injury $\cdot$ Somatostatin $•$ Heat Shock Protein $90 \cdot$ Glucocorticoid Receptor

\begin{abstract}
Background/Aims: Although it has been reported that somatostatin (SOM) upregulated the level of $90-k D$ heat shock protein (Hsp90), which participates in the inflammatory regulation by its client proteins, such as glucocorticoid receptor (GR), it remains unclear if it has a protective role against acute lung injury (ALI). Methods: ALI model was established by the injection of oleic acid $(\mathrm{OA})$ into the tail vein of mice. Lung injury was assessed by histological analysis, lung water content and arterial blood gases. The levels of Hsp90 and GR, the binding capacity and the affinity of GR were examined. Results: It was showed that pretreatment with SOM significantly increased Hsp90 levels and alleviated lung injuries in OA-injected mice. Furthermore, SOM increased the GR expression and improved the affinity of the GR in animals with lung injury. However, little alteration was found in the maximum binding capacity of the GR in mice with or without SOM. Conclusion: The data indicate SOM exerts a protective effect by increasing Hsp90 abundant and further enhancing the affinity of the GR. The beneficial effects of SOM treatment provide a new strategy for modulation of GR efficiency and alleviation of acute lung injury.

(C) 2016 The Author(s)

Published by S. Karger AG, Basel
\end{abstract}

\section{Introduction}

Acute lung injury (ALI) and its severe form, acute respiratory distress syndrome (ARDS), are critical illnesses with high morbidity and mortality. Despite the advances in

Y. Zhao and M. Zhang contributed equally to this work. 


\section{Cellular Physiology Cell Physiol Biochem 2016;38:1354-1364 \begin{tabular}{l|l|l} 
and BOI: 10.1159/000443079 & $\begin{array}{l}\text { C) 2016 The Author(s). Published by S. Karger AG, Basel } \\
\text { www.karger.com/cpb }\end{array}$
\end{tabular} \\ Zhao et al.: SOM Alleviates OA-Induced ALI via Hsp90}

the strategies targeting cell growth factors, complements, antioxidants, signal transduction inhibitor [1, 2] and stem cell [3, 4], no specific treatment exists for these diseases. Recently, several lines of evidence showed that somatostatin (SOM) has protective effects against central nervous system, pancreatic and gastrointestinal tract diseases [5-7], but the role of SOM in ALI remains to be clarified.

Interestingly, SOM also plays an inhibitory role in the effect of calpain, an enzyme that degrades Hsp90, in rat brain [8], which indicates the possibility that SOM could upregulate the Hsp90 level. Heat shock proteins play an important role under various stresses (trauma, operation, radiation, tumor, etc.) and maintain the internal homeostasis. Recent studies have found that Hsp90 participates in innate immunity and in the signaling pathways of many inflammatory factors, in addition to aiding damaged proteins in achieving their proper folding as a chaperone molecular. Moreover, pre-elevated levels of heat shock proteins help to attenuate organic injuries and reduce mortalities in various kinds of animal models and cellular experiments [9-11]. Among many Hsp90 clients, the glucocorticoid receptor (GR) which is a key effector in the hypothalamic-pituitary-adrenal axis (HPA axis) shows an important regulatory function under stresses. The participation of Hsp90 is indispensable for the activity of the GR. Treatment with specific Hsp90 inhibitors, such as geldanamycin, or mutant constructs of Hsp90 can lead to decrease of nuclear translocation of the GR and further significantly decrease its effects [12]. Glucocorticoids (GCs) are extensively used as anti-inflammatory agents in clinical treatments and experimental researches of animal in various inflammatory lung diseases [13-16], and they are closely associated with the duration of intensive care unit stay and ALI survivors' physical outcomes [17-21].

Therefore, SOM might have a protective effect on ALI in mice via elevating the Hsp90 level and then enhancing the activity of GR, which is a main protective factor against the development of ALI. To confirm this hypothesis, the present study explored the effect of SOM on ALI, levels of Hsp90 and GR, the affinity and the binding capacity of GR using an oleic acidinduced ALI model. This work will identify the protective role of SOM in ALI and provide an alternative strategy to our knowledge for the improving of the outcomes of ALI and ARDS with reduced side effects of GCs.

\section{Materials and Methods}

\section{Animals and drugs treatment}

A total of 120 male Kunming mice weighing 18-25g (purchased from Shanghai Laboratorial Animal Center, China) were housed in a 12-h light-dark cycle facility and allowed free access to food and water. Animals were randomized into three groups: OA group, SOM group and SOM+OA group. Animals were administered intraperitoneally with SOM (Sigma-Aldrich Co., USA) at the doses of 0.1, 1 and $10 \mu \mathrm{g} / \mathrm{g}$ body weight in the dose dependent experiment and at a dose of $1 \mu \mathrm{g} / \mathrm{g}$ in the rest of the experiments. Mice in OA group were injected with pure OA (Sigma-Aldrich Co., USA) slowly through the tail veins at a volume of $0.6 \mathrm{ml} / \mathrm{kg}$ by a Micro Sample instrument to induce acute lung injury, and saline was administered $30 \mathrm{~min}$ before OA injection as vehicle treatment. In SOM+OA group, animals received SOM $(1 \mu \mathrm{g} / \mathrm{g}) 30 \mathrm{~min}$ before OA $(0.6 \mathrm{ml} / \mathrm{kg})$ injection $[22,23]$. All procedures were approved by Experimental Animal Ethics Committee at the Third Military Medical University (TMMU) and performed in accordance with the TMMU guidelines for the care and use of experimental animal which are consistent with the NIH guidelines.

\section{Histological analysis}

Animals were anesthetized with $1.5 \%$ sodium pentobarbital. The lungs were isolated and fixed in $4 \%$ paraformaldehyde. Paraffin-embedded tissues were sectioned, mounted, stained with hematoxylin and eosin. Images were obtained using a Leica light microscope.

Lung/body weight ratio and wet/dry lung weight ratio

Lung/body weight ratio and wet/dry lung weight ratio were measured as indicators of pulmonary edema. Mice were euthanized with an overdose of sodium pentobarbital at the designated time points and 


\section{Cellular Physiology Cell Physiol Biochem 2016;38:1354-1364 \begin{tabular}{l|l} 
and Biochemistry Published online: March 24, 2016 & $\begin{array}{l}\text { DO 2016 The Author(s). Published by S. Karger AG, Basel } \\
\text { www.karger.com/cpb }\end{array}$
\end{tabular} \\ Zhao et al.: SOM Alleviates OA-Induced ALI via Hsp90}

the lungs were excised immediately after animals died. Lung/body weight ratio was calculated by the body and the wet lung weights. The lungs were weighted before and after they were dried to a constant weight at $80^{\circ} \mathrm{C}$ for $72 \mathrm{~h}$ to determine wet/dry lung weight ratio.

\section{Arterial blood gas analysis}

Arterial blood gas analysis is important to evaluate the condition of animals with acute lung injury. Mice were anesthetized with sodium pentobarbital $(50 \mathrm{mg} / \mathrm{kg})$ and a $0.3-\mathrm{ml}$ arterial blood sample was collected with a heparinized syringe from the abdominal aorta of each animal. The pH value, partial pressures of oxygen $\left(\mathrm{PaO}_{2}\right)$ and carbon dioxide $\left(\mathrm{PaCO}_{2}\right)$ were measured with an IL1302-type blood gas analysis instrument (Instrumentation Laboratory Inc.) immediately after blood samples were collected.

\section{Western blot analysis}

Cytoplasmic protein was isolated from lung tissues as previously described with modifications [24]. Samples were separated on a 10\% SDS-polyacrylamide gel, transferred to PVDF membrane and probed with the rabbit anti-Hsp90 and anti-GR (Santa Cruz, USA) primary antibodies. The samples were then incubated with goat anti-rabbit secondary antibody conjugated with horseradish peroxidase (Santa Cruz, USA) and detected with an ECL substrate kit (Thermo Scientific, USA). In these experiments, $\beta$-actin (Santa Cruz, USA) served as an endogenous control. The intensity of the bands was analyzed by a UVP Bio-imaging acquisition and image analysis system (Ultra-Violet Products Ltd, UK).

The mRNA expression of Hsp84, Hsp86 and IL-6

The mRNA level of Hsp84 and Hsp86, two subtypes of Hsp90 in mice, and IL-6 were examined. Total RNA was isolated from the lung tissues at the indicated time points using Trizol (Invitrogen, USA) and then reverse-transcribed into cDNA using the GoScript ${ }^{\mathrm{TM}}$ Reverse Transcription System (Promega, USA) according to the manufacturer's instructions. Real-time PCR was performed in a Stratagene Mx3000P system (Stratagene, USA). The following primers were used, forward: 5' AAT GGA GGA GAG CAA GGC AAA G 3', reverse: 5' GCC ATC ATG TAG CCC ATT GTA G 3' for Hsp84, forward: 5' GAG GCT GAC AAG AAT GAC 3', reverse: 5' TCT TCC ATG CGT GAT GTG 3' for Hsp86, forward: 5' CCA GAA ACC GCT ATG AAG 3', reverse: 5' TTC CAC GAT TTC CCA GAG 3' for IL-6 and forward: 5'AGG TTG TCT CCT GCG ACT TCA3', reverse: 5'TGG TCC AGG GTT TCT TAC TCC 3' for GAPDH. Samples were normalized to GAPDH.

\section{Glucocorticoid receptor binding assays}

Saturation binding assays were performed to test the affinity (indicated by Kd value) and the binding capacity (indicated by maximum binding capacity) of GR to $\left[{ }^{3} \mathrm{H}\right]$-dexamethasone, a synthesized glucocorticoid. The lung tissues from different treatment groups were homogenized in the lysis buffer (25mM Sucrose, $25 \mathrm{mM} \mathrm{KCl}, 1 \mathrm{mM} \mathrm{MgCl}_{2}, 1.5 \mathrm{mM} \mathrm{CaCl}, 10 \mathrm{mM}$ Sodium Molybdate, 50mM Tris, 0.5M 1,10-Phenanthroline, $0.5 \mathrm{M}$ Iodoacetamide and $2 \mathrm{M}$ Pepstatin A) followed by centrifugation at $170,000 \mathrm{~g}$ for 20 minutes at $4^{\circ} \mathrm{C}$. Homogenates used for saturation binding assay were incubated with [ $\left.{ }^{3} \mathrm{H}\right]$-dexamethasone (D6310, Sigma) alone and in the presence of 1000 -fold excess unlabeled dexamethasone for $20 \mathrm{~min}$ at $23^{\circ} \mathrm{C}$ with a $400-\mu \mathrm{L}$ total volume. Following incubation, homogenates were resuspended in 5-mL scintillation cocktail and then counted using a LS 6500 Liquid Scintillation Counter (Beckman Coulter, USA). The data from each assay were analyzed according to the method of Scatchard.

\section{Statistical analysis}

One-way analysis of variance and a Bonferroni post hoc test were used for multiple comparisons. Data are indicated as means \pm S.D. and the differences are considered to be statistically significant at $p<0.05$.

\section{Results}

Effects of SOM on lung histology

In the OA-induced ALI model, obvious pulmonary edema and hemorrhage were found at 3 and $12 \mathrm{~h}$ post injury by histological analysis. A marked infiltration of inflammatory cells (a number of neutrophils) and thickening of alveolar walls were observed at 1, 3 and 


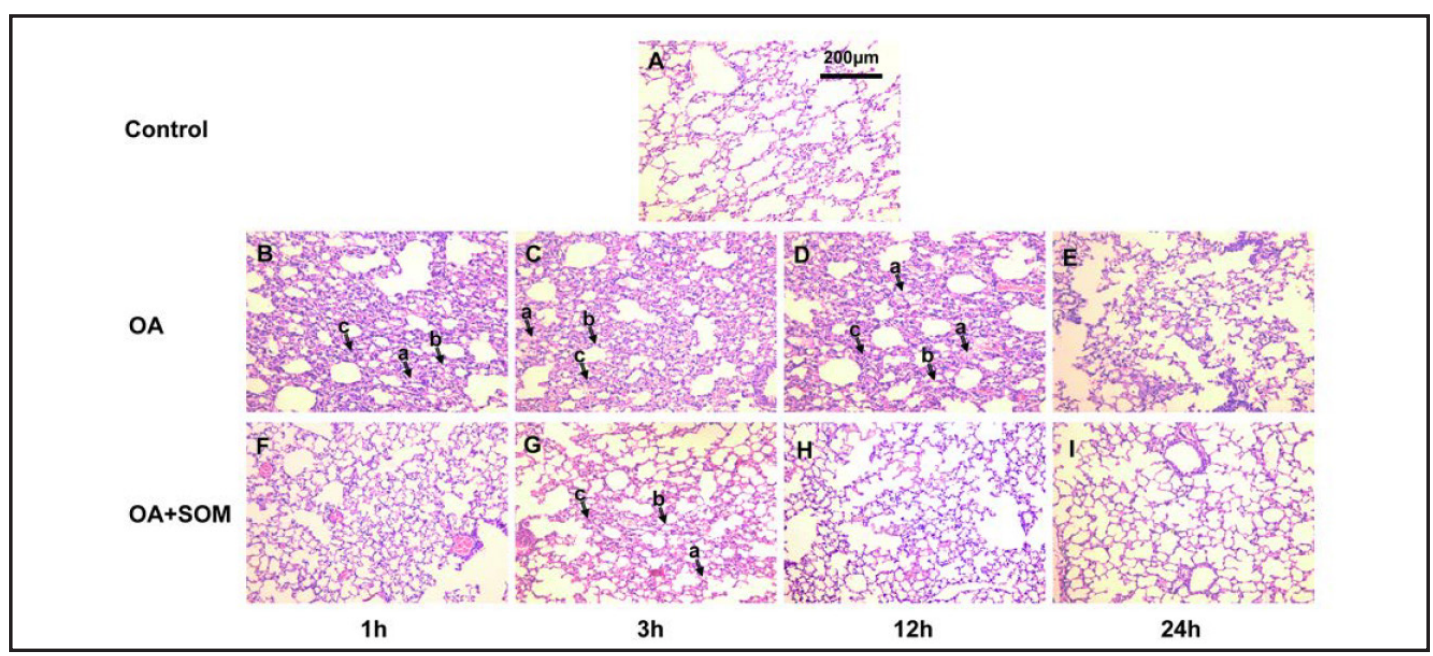

Fig. 1. Effect of SOM on lung histology. A significant edema (marked with Arrow a) appeared at 1, 3 and $12 \mathrm{~h}$ after OA injection. A thickening alveolar septum (marked with Arrow b) and marked infiltration of inflammatory cells (marked with Arrow c) were also observed after administration of OA. Lung sections were stained with hematoxylin and eosin. Magnification, $\times 200$. A indicated control, B-E indicated OA group and $\mathrm{F}-\mathrm{I}$ indicated $\mathrm{OA}+\mathrm{SOM}$ group from 1 to $24 \mathrm{~h}$ respectively.

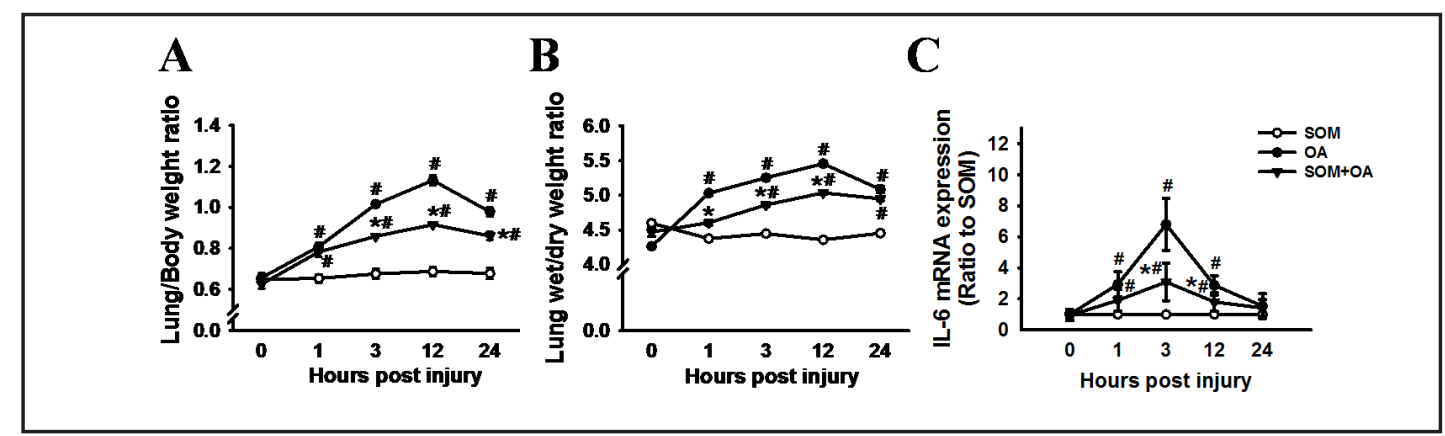

Fig. 2. Effects of SOM on the lung injuries. Lung/body weight ratio (A), wet/dry lung weight ratio (B) and IL-6 mRNA expressions (C) of mice were measured at 1, 3, 12 and $24 \mathrm{~h}$ post injury as described in the Methods section. ${ }^{*} \mathrm{P}<0.05$, SOM $+\mathrm{OA}$ versus $\mathrm{OA},{ }^{*} \mathrm{P}<0.05$, versus $0 \mathrm{~h}$. Data are expressed as the means $\pm \mathrm{S} . \mathrm{D}$. ( $\mathrm{n}=5$ per group, one-way ANOVA followed by Bonferroni post hoc test).

$12 \mathrm{~h}$ and a disorganized alveolar structure were found at $24 \mathrm{~h}$ after injury. SOM treatment prior to OA injection significantly alleviated pulmonary edema, hemorrhage and neutrophil accumulation compared to saline-treated animals in OA group (Fig. 1).

Effects of SOM on the lung injury

To investigate the effects of SOM on the pulmonary edema in mice, the lung/body ratio and wet/dry lung weight ratio were examined. Results showed both the lung/body and wet/ dry lung weight ratio were gradually increased from 1 to $12 \mathrm{~h}$ and slightly dropped at $24 \mathrm{~h}$ in OA-administered animals with or without SOM pretreatment. However, data revealed that the lung/body ratio in animals pre-treated with SOM prior to OA injection was significantly decreased at 3, 12 and $24 \mathrm{~h}$ compared to those of SOM-untreated OA group ( $<<0.05$ )(Fig. 2 A). Similarly, SOM treatment decreased the wet/dry lung weight ratio significantly at 1 , 3 and $12 \mathrm{~h}(\mathrm{p}<0.05)$ (Fig. 2B). Moreover, SOM significantly decreased the IL-6 mRMA level at 3 and 12 h post injury in OA-induced ALI animals ( $p<0.05$ ) (Fig. 2C). Thus, these results revealed the $\mathrm{SOM}$ pretreatment mitigated the lung injury induced by $\mathrm{OA}$ injection. 


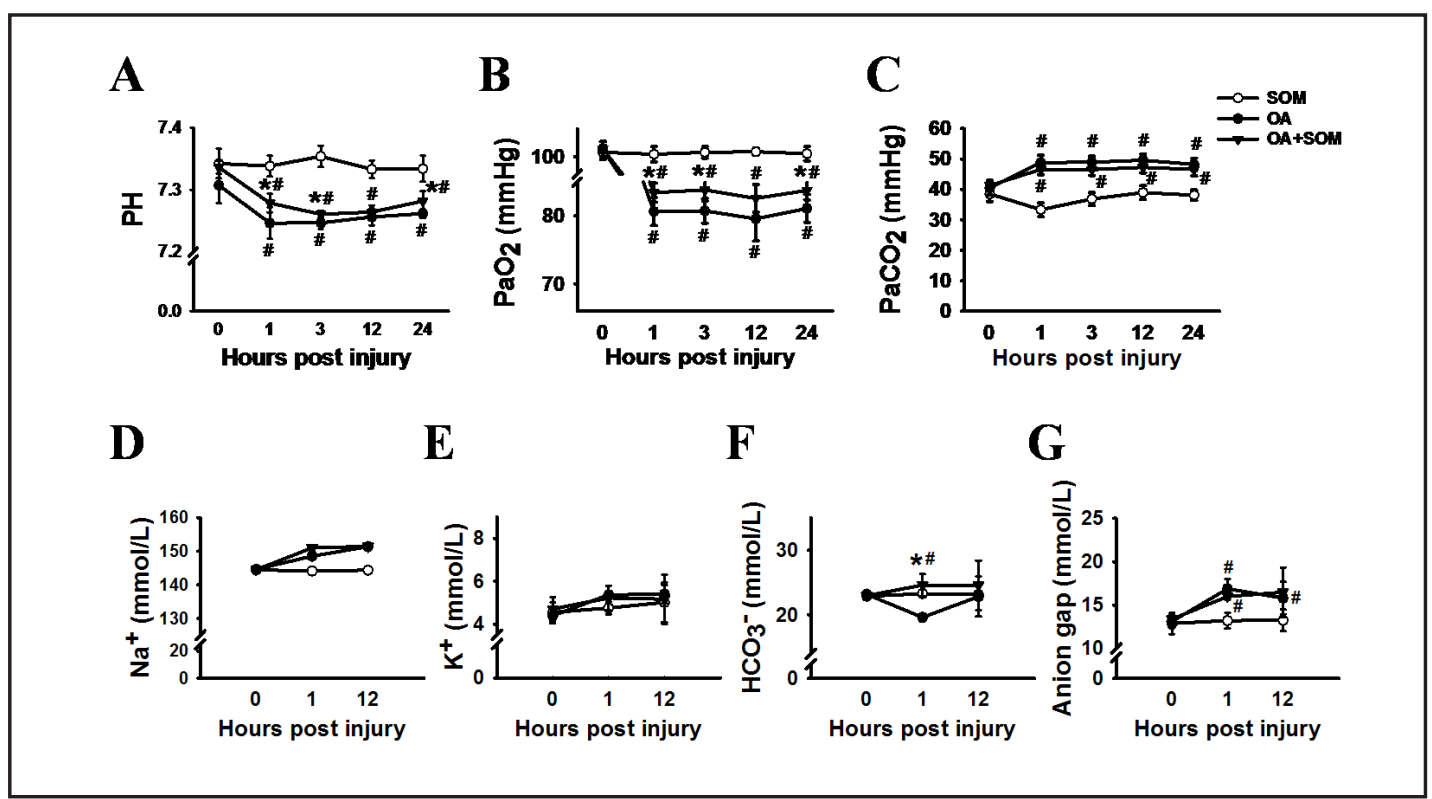

Fig. 3. Effects of SOM on the arterial blood gas and biochemical test. The experimental animals were anesthetized with sodium pentobarbital and a $0.3-\mathrm{ml}$ arterial blood sample collected from abdominal aorta with a heparinized syringe. $\mathrm{PH}$ value (A), $\mathrm{PaO}_{2}(\mathrm{~B}), \mathrm{PaCO}_{2}$ (C), $\mathrm{Na}^{+}(\mathrm{D}), \mathrm{K}^{+}(\mathrm{E}), \mathrm{HCO}_{3}{ }^{-}$(F) and anion gap (G) at designed time points were tested. ${ }^{*} \mathrm{P}<0.05$, SOM+OA versus $\mathrm{OA}$, ${ }^{\#} \mathrm{P}<0.05$, versus $0 \mathrm{~h}$. Data are expressed as the means \pm S.D. ( $n=5$ per group, one-way ANOVA followed by Bonferroni post hoc test).

\section{Arterial blood gas analysis and biochemical test}

Arterial blood gas analysis which is used to characterize the type of disorder and quantify the magnitude of lung injury was performed to evaluate the influences of SOM on $\mathrm{OA}$-induced lung injury. When mice were administered with $\mathrm{OA}, \mathrm{pH}$ value and $\mathrm{PaO}_{2}$ were decreased significantly from 1 to $24 \mathrm{~h}$ after injection. Animals with SOM treatment prior to OA injection had an increased $\mathrm{pH}$ value compared with those without SOM pretreatment at $1 \mathrm{~h}(p=0.04), 3 \mathrm{~h}(p=0.027)$ and $24 \mathrm{~h}(p=0.032)$ (Fig. 3A). The $\mathrm{PaO}_{2}$ value was also increased after SOM treatment in ALI mice at $1 \mathrm{~h}(p=0.036), 3 \mathrm{~h}(p=0.022)$ and $24 \mathrm{~h}(p=0.044)$ post injury (Fig. 3B). In contrast, animals had an increased $\mathrm{PaCO}_{2}$ in $\mathrm{OA}$ group, and there is no significant difference between $\mathrm{OA}$ and SOM+OA group from 1 to $24 \mathrm{~h}$ (Fig. 3C). Above data indicated that mice presented obvious dysfunction of gas exchange in OA-induced lung injury model and SOM pretreatment alleviated the disorder in $\mathrm{pH}$ value and $\mathrm{PaO}_{2}$ at 1,3 and $24 \mathrm{~h}$ after injury. In addition, the results showed the concentrations of $\mathrm{Na}^{+}$and $\mathrm{K}^{+} \mathrm{kept}$ unchanged in all three groups (Fig. 3D and 3E). But $\mathrm{HCO}_{3}^{-}$concentration decreased and anion gap increased significantly $1 \mathrm{~h}$ post injury in mice with ALI (Fig. 3F and 3G). Our data indicated acidosis presented at $1 \mathrm{~h}$ post injury in ALI animals and SOM obviously alleviated this pathological change.

\section{Effects of SOM on Hsp90 expression}

We used three SOM dosages (0.1, 1 and $10 \mu \mathrm{g} / \mathrm{g}$ body weight) and found it dosedependently increased Hsp90 level at $12 \mathrm{~h}$ in mice with lung injury induced by $\mathrm{OA}(\mathrm{P}<0.05)$ (Fig. 4A and 4B). Thus, based on published method for dose conversion from human to mice [25] and our results, we chose to use the dose of $1 \mu \mathrm{g} / \mathrm{g}$ in the present experiments. Hsp90 level was increased at 1,3 and $12 \mathrm{~h}$ after injury in response to $\mathrm{OA}(\mathrm{P}<0.05)$. Similarly, it was increased from 1 to $24 \mathrm{~h}$ in animals with SOM pretreatment before OA injection $(\mathrm{P}<0.05)$. Moreover, SOM alone increased Hsp90 from 1 to $24 \mathrm{~h}$ after injury (Fig. 4C and 4D). These data demonstrated that SOM produced a significant increase in Hsp90 level in both normal and injured animals. 
A

C

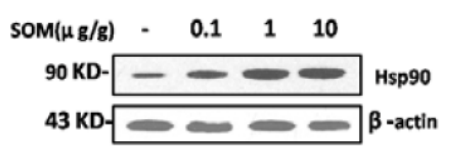

SOM

$\mathrm{OA}$

$\mathrm{OA}+\mathrm{SOM}$

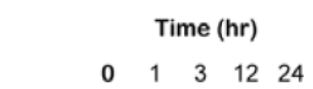

90kD- $-(-\cdots-\infty$ HSP90

43kD. $-1--1$-actin

90kD- $-\cdots-\infty$ HSP9O

43kD. $-\infty-\infty-a c t i n$

90kD- $-0-\cdots$ HSP9O

43kD. $-\infty-a c t i n$

E

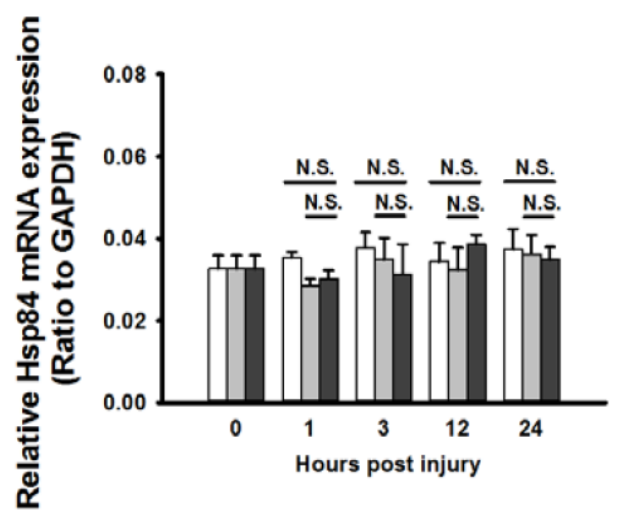

B

D

$\mathrm{F}$
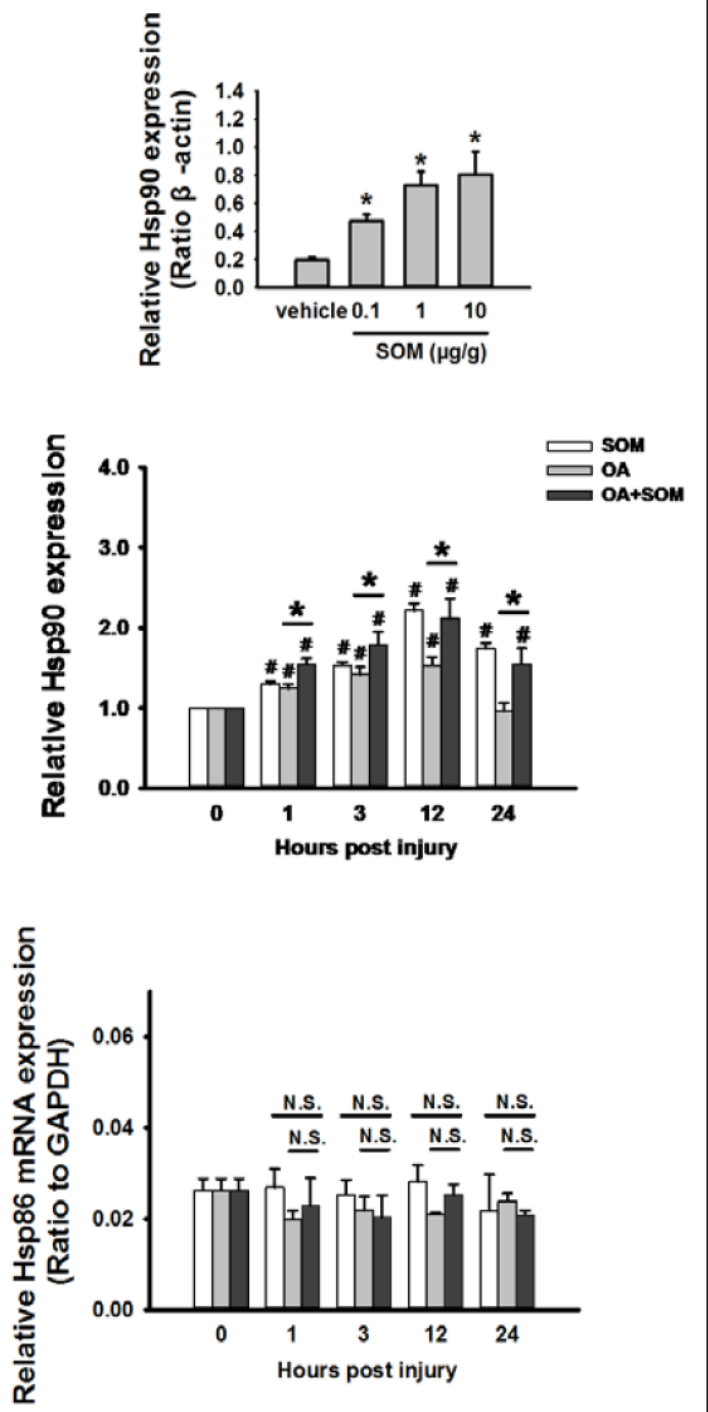

Fig. 4. The expression of heat shock proteins. Representative results of western blot (A) and relative Hsp90 expression (B) in mice treated with SOM $(0.1,1$ and $10 \mu \mathrm{g} / \mathrm{g}$ body weight) at $12 \mathrm{~h}$ post injury were shown $(\mathrm{n}=3)$. Representative results of western blot and the drugs administration (C) and relative Hsp90 expression (D) at 1, 3, 12 and $24 \mathrm{~h}$ were shown ( $\mathrm{n}=5$ ). The mRNA levels of Hsp84 (E) and Hsp86 (F) (two subtypes of Hsp90 in mice) were measured by q-PCR at designed time points ( $\mathrm{n}=5)$. Data were normalized to GAPDH. ${ }^{*} \mathrm{P}<0.05$, SOM+OA versus $\mathrm{OA},{ }^{,} \mathrm{P}<0.05$, versus 0 h, N.S. indicates no significant difference between indicated groups. Data are expressed as the mean \pm S.D. (one-way ANOVA followed by Bonferroni post hoc test).

In order to confirm whether the changes of Hsp90 derived from the alteration of its mRNA levels, we examined the mRNA levels of Hsp84 and Hsp86, two subtypes of Hsp90 in mice. However, the data showed that there was no significant difference between the $\mathrm{OA}$ and $\mathrm{OA}+\mathrm{SOM}$ groups or SOM and $\mathrm{OA}+\mathrm{SOM}$ groups (Fig. 4E and $4 \mathrm{~F}$ ). It suggests that the upregulation of Hsp90 protein is not due to the changes at the translational level.

\section{Effects of SOM on GR expression}

Due to the importance of GR for inflammation and our recent findings that the nuclear translocation of GR could be regulated by Hsp90, western blot analyses of GR were performed.

We found that the GR level increased temporarily at $1 \mathrm{~h}$, then decreased gradually from 3 to $12 \mathrm{~h}$ after OA administration. SOM-treated animals with OA injection had a higher GR 
$\mathbf{A}$

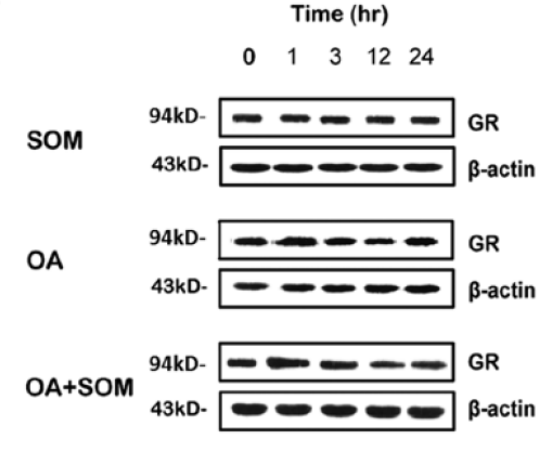

B

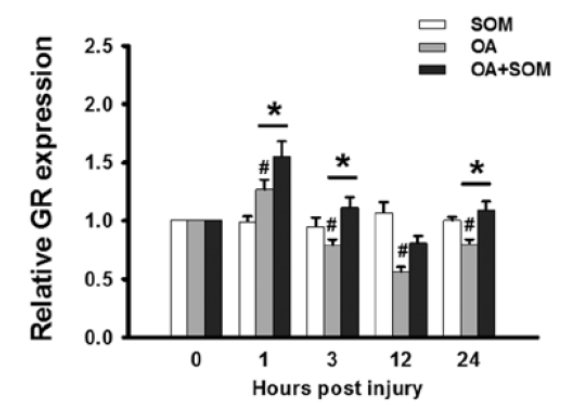

Fig. 5. The expression of glucocorticoid receptor. Representative results of western blot (A) and the statistical data (B) at $1,3,12$ and 24 h were shown. ${ }^{*} \mathrm{P}<0.05$, SOM+OA versus $0 A,{ }^{*} \mathrm{P}<0.05$, versus 0 h. Data are expressed as the mean \pm S.D. ( $n=5$ per group, one-way ANOVA followed by Bonferroni post hoc test).

A

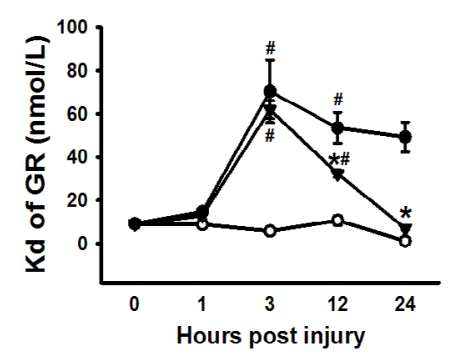

B

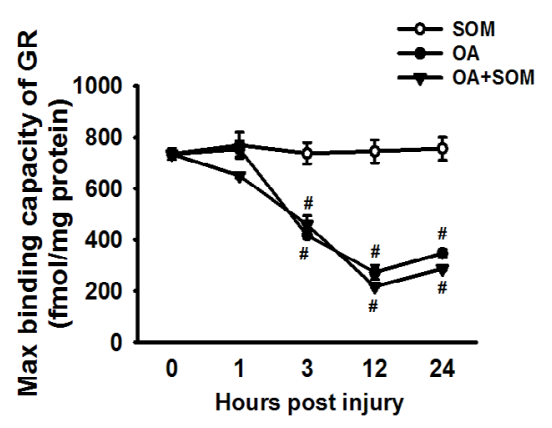

Fig. 6. The binding capacity and the affinity of GR. Kd value (A) and max binding capacity (B) of GR were tested at $1,3,12$ and $24 \mathrm{~h}$ post injury by $\left[{ }^{3} \mathrm{H}\right]$-dexamethasone radioligand binding assay. ${ }^{*} \mathrm{P}<0.05, \mathrm{SOM}+\mathrm{OA}$ versus $\mathrm{OA}$; $\mathrm{P}<<0.05$, versus $0 \mathrm{~h}$. Data are expressed as the mean \pm S.D. ( $\mathrm{n}=4$ per group, one-way ANOVA followed by Bonferroni post hoc test).

expression at 1, 12 and $24 \mathrm{~h}$ compared to the SOM-untreated mice in OA group. Unlike the expression of Hsp90 protein, SOM had no effect on GR protein under normal condition (Fig. $5 \mathrm{~A}$ and $5 \mathrm{~B})$.

\section{Effects of SOM on ligand-binding ability of GR}

In order to determine if SOM affects ligand binding to the GR, saturation binding assays were performed using $\left[{ }^{3} \mathrm{H}\right]$-dexamethasone, a ligand of glucocorticoid receptor, and the dissociation constant (Kd) and the maximum number of binding sites (Bmax) were calculated. As shown in Fig. 6, the Kd values of the GR increased at 1 and $3 \mathrm{~h}$ post-injury and were resolving subsequently at 12 and $24 \mathrm{~h}$. The Kd values of SOM+OA group were profoundly lower than OA group (Fig. 6A). Moreover, the maximal numbers of binding sites (Bmax) of the GR were decreased from 3 to $24 \mathrm{~h}$ within the OA group and there was no obvious difference for Bmax of the GR between the SOM+OA group and OA group across all time points in an acute lung injury model (Fig. 6B).

\section{Discussion}

The OA model is one of the three most widely used animal models (broncho-alveolar lavage, OA injection and LPS injection) in research concerning acute respiratory diseases, such as acute lung injury and acute respiratory distress syndrome [26, 27]. This model causes 


\section{Cellular Physiology Cell Physiol Biochem 2016;38:1354-1364 \\ \begin{tabular}{l|l} 
and Biochemistry Published online: March 24, 2016 & $\begin{array}{l}\text { (c) 2016 The Author(s). Published by S. Karger AG, Basel } \\
\text { www.karger.com/cpb }\end{array}$
\end{tabular} \\ Zhao et al.: SOM Alleviates OA-Induced ALI via Hsp90}

the increasing in the permeability in endothelial cells and impairs gas exchange [28-30].

In the present study, the results showed that OA treatment resulted in a strong lung inflammation which was characterized by vascular leakage. The changes were determined by the presence of lung edema and strong leukocyte infiltration into the lung and also occur in patients with ALI. The IL-6 level was increased significantly in OA-induced ALI animals. This is in agreement with previous studies, which found SOM inhibits secretion of IL-6 in ALI mice [31] and IL-8 and IL-1 $\beta$ from the intestinal epithelial cells [32]. SOM intervention significantly alleviated the OA-induced lung injuries, indicating it could be an effective method for ALI treatment. Although published documents reported that the effects of anesthesia on murine models of lung injury should be considered, the dosage $50 \mathrm{mg} /$ $\mathrm{kg}$ ) we used is a relatively low dose in mice [33] and no pentobarbital-induced death was observed in the present study. The $\mathrm{O}_{2}$ saturation $\left(\mathrm{SPO}_{2}\right)$ at this dose is approximately $90 \%$ at 35-40 min after anesthesia [34], which would not have a significant effect on ALI.

In addition, our data demonstrated that the levels of Hsp90 were markedly increased from 1 to $12 \mathrm{~h}$ with $\mathrm{OA}$ injection alone due to the intrinsic protection of organs when they suffered insults and SOM treatment dramatically increased Hsp90 level in animals with lung injury. It also showed that Hsp90 level was increased in animals with SOM treatment alone. The heat shock response has been classically defined as a highly conserved cellular defense mechanism. It has been well documented that pre-condition of heat shock restored alveolar fluid clearance in cultured alveolar type II cells and alveolar macrophages [35, 36]. Heat shock proteins also had the similar effect on the animals with lung injury induced by sepsis [37] and ischemia-reperfusion [38].

In this study, though the level of Hsp90 was increased in OA-induced lung injury, it was insufficient to cope with the severe injury. In addition, increases in Hsp90 protein appeared as early as $1 \mathrm{~h}$ after injury, and the mRNA level of Hsp84 and Hsp86 kept unchanged in all three groups, which implied that the upregulation of Hsp90 was not caused by de novo synthesis. Interestingly, recent data showed that calpain could cause Hsp90 cleavage in several cell systems and its activity is inhibited by SOM via blocking of $\mathrm{Ca}^{2+}$ channels [39-41]. Therefore, SOM-induced increase in Hsp90 level might due to the inhibition of its degradation, which has a distinct mechanism from the elevation of Hsp90 level triggered by heat stress.

In addition to functioning as a chaperone, increased Hsp90 would affect the activity of its clients. Hsp90 is also required for GR to bind their ligands and exert anti-inflammatory action [42]. Thus, it is possible that the increased Hsp90 protect mice from acute lung injury via improving the activity of GR.

Here, we showed that SOM had no effect on the GR expression in mice without lung injury. Nevertheless, SOM pretreated animals had a significantly higher GR level at 1, 3 and $24 \mathrm{~h}$ compared to OA group. Moreover, the Kd value of GR was increased at 12 and $24 \mathrm{~h}$, and almost reached the normal level at $24 \mathrm{~h}$, which implied that the protective action of GR in lung injury was associated closely with its affinity at 12 and $24 \mathrm{~h}$. It might because the level of GR at these time points was insufficient to meet the needs for the body to maintain the balances of internal environment, and the enhanced affinity of GR was beneficial to the supplement of GR effects.

In addition, during OA-induced acute lung injury the binding capacity of GR was reduced strongly because Hsp90 is largely consumed during the recovery of misfolded proteins. In this case, it was undoubtedly important that the Hsp90 level was increased rapidly by blocking its degradation and further promoting the function of the GR. The present study demonstrated that the binding capacity was not a key factor accounting for the altered activity of the GR. Thus, the affinity of the GR was separately enhanced without alteration of the binding capacity at 12 and $24 \mathrm{~h}$ in this case. However, SOM exerted positive effects at an early stage via increasing the expression of GR, especially at 1 and $3 \mathrm{~h}$ after injury.

So far, several lines of evidence have showed that SOM exerts a protective action in inflammatory response. Exogenous SOM has been demonstrated to inhibit vasodilatation [43] and plasma protein extravasation [44]. Another study revealed that SOM inhibited the function of several types of cells which are able to produce pro-inflammatory mediators 


\section{Cellular Physiology Cell Physiol Biochem 2016;38:1354-1364

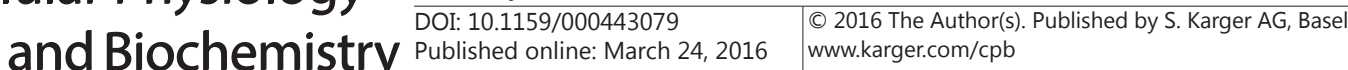 \\ Zhao et al.: SOM Alleviates OA-Induced ALI via Hsp90}

[32]. In addition, it's well known that GR as a nuclear factor play an important role in inflammatory response via regulating the target genes related to inflammation. Taken above factors into account, we think it is possible that the inhibition effect of SOM on inflammatory mediators is modulated by GR activity, at least partly.

Besides the mechanism we found in the present experiments, the differences in genetic background could also alter the function of GR. Our previous study has found the mutation in Hsp84 gene affect the nuclear translocation of GR [12]. Another study found the key structure of GR domain mutations would also change its function. For example, the mutations located at hormone combined domain can reduce affinity of GR to its ligand [45]. In addition, hypothalamo-pituitary-adrenocortical (HPA) axis dysregulation [46] and an excessively high concentration of endogenous cortisol and administered steroid drugs [47] could alter the expression and activity of GR. These factors could not be excluded in the current experiments.

In summary, we demonstrate that SOM exerts a protective action against OA-induced ALI in mice. It is a positive regulatory drug for GR efficiency because it rapidly promotes increases in Hsp90 level and further in the activity of GR. Though glucocorticoid is an extensively used and effective drug, the overdose of it causes several severe side effects, such as osteoporosis and inhibition of the HPA axis by negative feedback. SOM could improve the affinity of GR to its ligand, which provides a better way for experimental research on improving the effect of corticosteroids without increasing the dosage of the hormone.

\section{Acknowledgements}

This work was supported by the National Natural Science Foundation of China [Grant 30470988], the Foundation for the Author of National Excellent Doctoral Dissertation of China [Grant 200156], and National Basic Research Program of China [Grant 2005CB522602].

\section{Disclosure Statement}

The authors have declared that no conflict of interest exists.

\section{References}

1 Ji Y, Gao F, Sun B, Hao J, Liu Z: Angiotensin-converting enzyme 2 inhibits apoptosis of pulmonary endothelial cells during acute lung injury through suppressing smad2 phosphorylation. Cell Physiol Biochem 2015;35:2203-2212.

2 Bao H, Gao F, Xie G, Liu Z: Angiotensin-converting enzyme 2 inhibits apoptosis of pulmonary endothelial cells during acute lung injury through suppressing mir-4262. Cell Physiol Biochem 2015;37:759-767.

3 Guo W, Li Z, Xie X, Qin T, Wu Y, Li Z, Chai J, Yi F, Tan T, Zhu H, Wang S: Urinary trypsin inhibitor attenuates acute lung injury by improving endothelial progenitor cells functions. Cell Physiol Biochem 2015;36:10591068.

4 Yin X, Liang Z, Yun Y, Pei L: Intravenous transplantation of bmp2-transduced endothelial progenitor cells attenuates lipopolysaccharide-induced acute lung injury in rats. Cell Physiol Biochem 2015;35:2149-2158.

5 Sliwinska-Mosson M, Vesely M, Milnerowicz H: The clinical significance of somatostatin in pancreatic diseases. Ann Endocrinol 2014;75:232-240.

6 Martin-Grace J, Tamagno G: Somatostatin analogs in the medical management of occult bleeding of the lower digestive tract. Gastroenterol Res Pract 2015;2015:702921.

7 Reubi JC, Schonbrunn A: Illuminating somatostatin analog action at neuroendocrine tumor receptors. Trends Pharmacol Sci 2013;34:676-688. 


\section{Cellular Physiology Cell Physiol Biochem 2016;38:1354-1364 \begin{tabular}{l|l} 
and Biochemistry & DOI: 10.1159/000443079 \\
Published online: March 24, 2016 & $\begin{array}{l}\text { C 2016 The Author(s). Published by S. Karger AG, Basel } \\
\text { www.karger.com/cpb }\end{array}$
\end{tabular} \\ Zhao et al.: SOM Alleviates OA-Induced ALI via Hsp90}

8 Averna M, Stifanese R, De Tullio R, Salamino F, Pontremoli S, Melloni E: In vivo degradation of nitric oxide synthase (nos) and heat shock protein 90 (hsp90) by calpain is modulated by the formation of a nos-hsp90 heterocomplex. FEBS J 2008;275:2501-2511.

9 Tominaga M, Ohta M, Kai S, Iwaki K, Shibata K, Kitano S: Increased heat-shock protein 90 expression contributes to impaired adaptive cytoprotection in the gastric mucosa of portal hypertensive rats. J Gastroenterol Hepatol 2009;24:1136-1141.

10 Latchman DS: Protective effect of heat shock proteins in the nervous system. Curr Neurovasc Res 2004;1:21-27.

11 Pribenszky C, Vajta G, Molnar M, Du Y, Lin L, Bolund L, Yovich J: Stress for stress tolerance? A fundamentally new approach in mammalian embryology. Biol Reprod 2010;83:690-697.

12 Zhao Y, Shen HY, Chen XY, Xiong RP, Li P, Liu P, Yang N, Zhou YG: Genetic variations of heat shock protein 84 in mice mediate cellular glucocorticoid response. Cell Physiol Biochem 2010;25:359-366.

13 Wang J, Zhang H, Su C, Chen J, Zhu B, Zhang H, Xiao H, Zhang J: Dexamethasone ameliorates h(2)s-induced acute lung injury by alleviating matrix metalloproteinase-2 and -9 expression. PLoS One 2014;9:e94701.

14 Umberto Meduri G, Bell W, Sinclair S, Annane D: Pathophysiology of acute respiratory distress syndrome. Glucocorticoid receptor-mediated regulation of inflammation and response to prolonged glucocorticoid treatment. Presse Med 2011;40:e543-560.

15 Marik PE, Meduri GU, Rocco PR, Annane D: Glucocorticoid treatment in acute lung injury and acute respiratory distress syndrome. Crit Care Clin 2011;27:589-607.

16 Diaz JV, Brower R, Calfee CS, Matthay MA: Therapeutic strategies for severe acute lung injury. Crit Care Med 2010;38:1644-1650.

17 Fan E, Dowdy DW, Colantuoni E, Mendez-Tellez PA, Sevransky JE, Shanholtz C, Himmelfarb CR, Desai SV, Ciesla N, Herridge MS, Pronovost PJ, Needham DM: Physical complications in acute lung injury survivors: A two-year longitudinal prospective study. Crit Care Med 2014;42:849-859.

18 Needham DM, Wozniak AW, Hough CL, Morris PE, Dinglas VD, Jackson JC, Mendez-Tellez PA, Shanholtz C, Ely EW, Colantuoni E, Hopkins RO, National Institutes of Health NAN: Risk factors for physical impairment after acute lung injury in a national, multicenter study. Am J Respir Crit Care Med 2014;189:1214-1224.

19 Bienvenu OJ, Gellar J, Althouse BM, Colantuoni E, Sricharoenchai T, Mendez-Tellez PA, Shanholtz C, Dennison CR, Pronovost PJ, Needham DM: Post-traumatic stress disorder symptoms after acute lung injury: A 2-year prospective longitudinal study. Psychol Medicine 2013;43:2657-2671.

20 Schelling G, Kapfhammer HP: Surviving the icu does not mean that the war is over. Chest 2013;144:1-3.

21 Incerpi EK, Oliveira LM, Pereira EM, Soncini R: Inhibition of endogenous glucocorticoid synthesis aggravates lung injury triggered by septic shock in rats. Int J Exp Pathol 2015;96:133-139.

22 Elekes K, Helyes Z, Kereskai L, Sandor K, Pinter E, Pozsgai G, Tekus V, Banvolgyi A, Nemeth J, Szuts T, Keri G, Szolcsanyi J: Inhibitory effects of synthetic somatostatin receptor subtype 4 agonists on acute and chronic airway inflammation and hyperreactivity in the mouse. Eur J Pharmacol 2008;578:313-322.

23 Helyes Z, Pinter E, Sandor K, Elekes K, Banvolgyi A, Keszthelyi D, Szoke E, Toth DM, Sandor Z, Kereskai L, Pozsgai G, Allen JP, Emson PC, Markovics A, Szolcsanyi J: Impaired defense mechanism against inflammation, hyperalgesia, and airway hyperreactivity in somatostatin 4 receptor gene-deleted mice. Proc Natl Acad Sci USA 2009;106:13088-13093.

24 Shen HY, He JC, Wang Y, Huang QY, Chen JF: Geldanamycin induces heat shock protein 70 and protects against mptp-induced dopaminergic neurotoxicity in mice. J Biol Chem 2005;280:39962-39969.

25 Yuan-Pei Z, Huai-De S: Pharmacological experiment, ed 2. Beijing, People's Medical Publishing House, 1996.

26 Lopez-Aguilar J, Quilez ME, Marti-Sistac O, Garcia-Martin C, Fuster G, Puig F, Flores C, Villar J, Artigas A, Blanch L: Early physiological and biological features in three animal models of induced acute lung injury. Intensive Care Med 2010;36:347-355.

27 Wang HM, Bodenstein M, Markstaller K: Overview of the pathology of three widely used animal models of acute lung injury. Eur Surg Res 2008;40:305-316.

28 Vadasz I, Morty RE, Kohstall MG, Olschewski A, Grimminger F, Seeger W, Ghofrani HA: Oleic acid inhibits alveolar fluid reabsorption: A role in acute respiratory distress syndrome? Am J Respir Crit Care Med 2005;171:469-479.

29 Ashbaugh DG, Uzawa T: Respiratory and hemodynamic changes after injection of free fatty acids. J Surg Res 1968;8:417-423. 


\section{Cellular Physiology Cell Physiol Biochem 2016;38:1354-1364 \begin{tabular}{l|l} 
DOI: 10.1159/000443079 & and Biochemistry \\
Published online: March 24, 2016 & $\begin{array}{l}\text { O 2016 The Author(s). Published by S. Karger AG, Basel } \\
\text { www.karger.com/cpb }\end{array}$
\end{tabular} \\ Zhao et al.: SOM Alleviates OA-Induced ALI via Hsp90}

30 Crocker GH, Jones JH: Effects of oleic acid-induced lung injury on oxygen transport and aerobic capacity. Resp Physiol Neurobiol 2014;196:43-49.

31 Xu L, Liu Y, Han W, Nan C, Li D, Hong G, Zhao G, Lu Z: [influences and mechanisms of somatostatin on inflammation in endotoxin-induced acute lung injury mice]. Zhonghua wei zhong bing ji jiu yi xue 2014;26:315-320.

32 Chowers Y, Cahalon L, Lahav M, Schor H, Tal R, Bar-Meir S, Levite M: Somatostatin through its specific receptor inhibits spontaneous and tnf-alpha- and bacteria-induced il-8 and il-1 beta secretion from intestinal epithelial cells. J Immunol 2000;165:2955-2961.

33 Gargiulo S, Greco A, Gramanzini M, Esposito S, Affuso A, Brunetti A, Vesce G: Mice anesthesia, analgesia, and care, part i: Anesthetic considerations in preclinical research. ILAR 2012;53:E55-69.

34 Tsukamoto A, Serizawa K, Sato R, Yamazaki J, Inomata T: Vital signs monitoring during injectable and inhalant anesthesia in mice. Exp Anim 2015;64:57-64.

35 Howard M, Roux J, Iles KE, Miyazawa B, Christiaans S, Anjum N, Dickinson DA, Goolaerts A, Matthay MA, Pittet JF: Activation of the heat shock response attenuates the interleukin 1beta-mediated inhibition of the amiloride-sensitive alveolar epithelial ion transport. Shock 2013;39:189-196.

36 Howard M, Roux J, Lee H, Miyazawa B, Lee JW, Gartland B, Howard AJ, Matthay MA, Carles M, Pittet JF: Activation of the stress protein response inhibits the stat1 signalling pathway and inos function in alveolar macrophages: Role of hsp90 and hsp70. Thorax 2010;65:346-353.

37 Chatterjee A, Dimitropoulou C, Drakopanayiotakis F, Antonova G, Snead C, Cannon J, Venema RC, Catravas JD: Heat shock protein 90 inhibitors prolong survival, attenuate inflammation, and reduce lung injury in murine sepsis. Am J Respir Crit Care Med 2007;176:667-675.

38 Godzich M, Hodnett M, Frank JA, Su G, Pespeni M, Angel A, Howard MB, Matthay MA, Pittet JF: Activation of the stress protein response prevents the development of pulmonary edema by inhibiting vegf cell signaling in a model of lung ischemia-reperfusion injury in rats. FASEB J 2006;20:1519-1521.

39 Stalker TJ, Gong Y, Scalia R: The calcium-dependent protease calpain causes endothelial dysfunction in type 2 diabetes. Diabetes 2005;54:1132-1140.

40 Minami Y, Kimura Y, Kawasaki H, Suzuki K, Yahara I: The carboxy-terminal region of mammalian hsp90 is required for its dimerization and function in vivo. Mol Cell Biol 1994;14:1459-1464.

41 Bellocq A, Doublier S, Suberville S, Perez J, Escoubet B, Fouqueray B, Puyol DR, Baud L: Somatostatin increases glucocorticoid binding and signaling in macrophages by blocking the calpain-specific cleavage of hsp 90. J Biol Chem 1999;274:36891-36896.

42 Kirschke E, Goswami D, Southworth D, Griffin PR, Agard DA: Glucocorticoid receptor function regulated by coordinated action of the hsp90 and hsp70 chaperone cycles. Cell 2014;157:1685-1697.

43 Lembeck F, Donnerer J, Bartho L: Inhibition of neurogenic vasodilation and plasma extravasation by substance p antagonists, somatostatin and [d-met2, pro5] enkephalinamide. Eur J Pharmacol 1982;85:171176.

44 Szolcsanyi J, Pinter E, Helyes Z, Oroszi G, Nemeth J: Systemic anti-inflammatory effect induced by counterirritation through a local release of somatostatin from nociceptors. Br J Pharmacol 1998;125:916-922.

45 Hurt DE, Suzuki S, Mayama T, Charmandari E, Kino T: Structural analysis on the pathologic mutant glucocorticoid receptor ligand-binding domains. Mol Endocrinol 2016;30:173-188.

46 Li S, Liao Y, Wang L, Huang R, Yue J, Xu H, Zhou H, Lou Z, Hu Y, Liu W: Dysregulation of hypothalamopituitary-adrenocortical axis in overweight female diabetic subjects is associated with downregulation of corticosteroid receptors and 11beta-hsd1 in the brain. Horm Metab Res 2015; DOI: 10.1055/s-00351555902.

47 Bergquist M, Lindholm C, Strinnholm M, Hedenstierna G, Rylander C: Impairment of neutrophilic glucocorticoid receptor function in patients treated with steroids for septic shock. Intensive Care Med Exp 2015;3:59. 